\title{
When Marijuana is Used Before Cigarettes or Alcohol: Demographic Predictors and Associations with Heavy Use, Cannabis Use Disorder, and Other Drug-Related Outcomes
}

\author{
Brian J. Fairman ${ }^{1}$, C. Debra Furr-Holden², and Renee M. Johnson ${ }^{3}$ \\ ${ }^{1}$ Health Behavior Branch, Division of Intramural Population Health Research, Eunice Kennedy \\ Shriver National Institute of Child Health and Human Development, Bethesda, MD \\ ${ }^{2}$ Department of Epidemiology and Biostatistics, Michigan State University, East Lansing, MI \\ ${ }^{3}$ Department of Mental Health, John Hopkins Bloomberg School of Public Health, Baltimore, MD
}

\section{Abstract}

\begin{abstract}
Background-Recent loosening of state and federal policy restrictions on marijuana, along with changes in social norms regarding marijuana use and decreases in prevalence of other types of substance use, may lead to increases in youth initiating marijuana before other types of substances such as alcohol and tobacco. We investigated predictors and potential consequences of initiating marijuana before other drugs for youth aged 12-21-years in the US.
\end{abstract}

\begin{abstract}
Methods-Nationally-representative, cross-sectional survey data from the US National Survey on Drug Use and Health supplied self-reported age-of-first marijuana, cigarettes, alcohol, other tobacco, and other illegal drug use among 12-21-year-old samples from 2004 to 2014 $(n=275,559)$. We first examined the degree to which initiating marijuana use first was associated with sex, age, race/ethnicity, and survey year. Then, we examined whether using marijuana first predicted heavy marijuana use, cannabis use disorder (CUD), alcohol use disorder (AUD), nicotine dependence (ND), or lifetime use of other illegal drugs.
\end{abstract}

Results-Among all survey youth (substance users and non-users) the proportion using marijuana first increased from 4.8\% to $8.8 \%$ from 2004-2014. Those using marijuana first (versus alcohol or cigarettes first) were more likely to be male and older and Black, American Indian/ Alaskan Native, multiracial, or Hispanic than White or Asian. Among substance users and adjusting for age of onset and the number of substances used, using marijuana first was associated higher odds of heavy current marijuana use and CUD.

Corresponding Author: Brian J. Fairman, PhD, Division of Intramural Population Health Research, Eunice Kennedy Shriver National Institute of Child Health \& Human Development, 6710B Rockledge Dr., Bethesda, MD 20817, brian.fairman @ nih.gov.

Compliance with Ethical Standards

Disclosure of Potential Conflicts of Interest

The authors declare no conflict of interest.

Ethical Approval

The original study procedures were approved by RTI's Institution Review Board (IRB) for the protection of human subjects. Authors had only access to the publicly available, de-identified data, and thus this research was deemed 'not human subjects research' by the Johns Hopkins Bloomberg School of Public Health IRB.

Informed Consent

All survey participants were provided informed consent. 
Conclusions-In recent years, youth have been increasingly likely to use marijuana as their first drug and sequence of initiation is associated with race/ethnicity, gender, and age. Using marijuana first might increase the chance of heavy use and CUD.

\section{Keywords}

marijuana; cigarettes; alcohol; dependence; gateway

Initiation of tobacco and alcohol use usually precedes first of use of marijuana or other illegal drugs; this pattern has been characterized in the well-cited "gateway hypothesis" (D. B. Kandel \& Kandel, 2015; Kirby \& Barry, 2012; Ramo, Liu, \& Prochaska, 2012).

Behavioral neuropharmacology research suggests that nicotine may "prime" the brain to appreciate the reinforcing effects of extrinsic substances, such as alcohol or marijuana (E. R. Kandel \& Kandel, 2014). Importantly, priming could work in the reverse direction; meaning marijuana use could increase sensitivity to the rewarding effects of nicotine (Ellgren, Spano, \& Hurd, 2007; Panlilio, Zanettini, Barnes, Solinas, \& Goldberg, 2013). Therefore, whichever drug is used first could become a "gateway," in the sense that use could lead to use of other substances. Examining adolescents' drug sequences may enhance our understanding of factors that influence initiation of substance use, subsequent use of other substances, and drug-related outcomes.

The specific order of initiation of specific drugs used may vary based on several factors, including drug availability and legal status of drugs. Nationally-representative US data show that there have been steep declines in adolescent cigarette and alcohol use, contrasted by either relatively stable or periods of slightly increasing marijuana use (Johnson et al., 2015; Johnston, O’Malley, Miech, Bachman, \& Schulenberg, 2017; Nguyen, Ebnesajjad, Stuart, Kennedy, \& Johnson, 2018). Nearly twice as many 12-17-years-olds report past 30-day marijuana use vs. cigarette use (respectively, $6.5 \%$ and 3.4\%), whereas $9.2 \%$ report past 30day alcohol use (Substance Abuse and Mental Health Services Administration, 2017). These trends coincide with loosening of US state policies on marijuana use for adults, and implementation of multi-tiered efforts to curb underage cigarette and alcohol use (e.g., excise taxes, diversion prevention strategies) (Friend, Lipperman-Kreda, \& Grube, 2011; Hingson \& White, 2014). Consequently, today's youth may have higher levels of access and exposure to marijuana than previous generations and may be more likely to initiate marijuana use prior to tobacco or alcohol. Although data are limited, changes to the drug sequence could have implications for the future risk of substance use disorders (SUDs) and other drug-related outcomes. In this study, we investigated the trends, characteristics, and potential consequences of initiating marijuana before other substances among youth aged 12-21 years in the US, from 2004-2014.

There are only a handful of studies that have examined factors associated with initiating marijuana first, i.e., before tobacco, alcohol, or other substances. Studies of adults have shown that 18-30 year-olds are more likely to initiate marijuana before other substances than those older than 30 (Degenhardt et al., 2009, 2010; Wells \& McGee, 2008). Additionally, US studies have noted higher rates of using marijuana before tobacco or alcohol among Blacks (Green et al., 2016; Kennedy, Patel, Cheh, Hsia, \& Rolle, 2016; 
Sartor et al., 2013; Vaughn, Wallace, Perron, Copeland, \& Howard, 2008). This body of work has key limitations; most studies are based on adult (vs. adolescent) samples, were conducted outside the US, and/or used data that are at least 10-15 years old (Degenhardt et al., 2009; Green et al., 2016). The present study builds on what is known and will provide information about drug sequencing among adolescents within the modern context.

Studies have also examined whether initiating marijuana before other substances (typically tobacco or alcohol) influences later substance-related outcomes compared to the typical initiation sequence of tobacco and/or alcohol then marijuana, and there is mixed evidence supporting that initiating substance use with marijuana first is associated with adverse outcomes. One study conducted in a US adult female twin sample reported that using marijuana before alcohol was associated with a more rapid transition to marijuana-related problems (Sartor et al., 2013). A couple of studies, one conducted among 14-15-year-olds in Australia and another in a cohort of US adolescents, found that marijuana use increased the likelihood of smoking cigarettes and becoming tobacco dependent (Patton, Coffey, Carlin, Sawyer, \& Lynskey, 2005; Timberlake et al., 2007). Included in the present issue, Nguyen and colleagues (2018) analyses of AddHealth data show that adolescent marijuana use is a risk factor for later daily cigarette smoking among women. On the other hand, two studies conducted in US and New Zealand found that using marijuana before tobacco and alcohol was not associated with an increased odds of marijuana, alcohol, or tobacco dependence among users (Degenhardt et al., 2009; Wells \& McGee, 2008).

We build upon this literature by first identifying cross-sectional trends in the proportion of youth initiating marijuana before other substances and the demographic characteristics of such users. Next, we examined the degree to which initiating marijuana before other substances was associated with prevalent marijuana- and other drug-related outcomes: (1) daily or near daily marijuana use, (2) cannabis use disorder, (3) alcohol use disorder, (4) nicotine dependence, and (5) lifetime use of other drugs. A methodological innovation of our study allowed us to better differentiate the sequence of marijuana, cigarette, and alcohol onset when individuals self-report using two or more of these substances at the same age. In prior studies, even those based on prospective designs, the order of drug onset is based on self-reported age-of-first use or onset between successive follow-ups. Ties where age-of-first use coincide can be as high as 20-30\% (Kennedy et al., 2016; Sartor et al., 2013). Studies often either exclude such ties, treat them as a separate group, or do not disclose how they are treated (Golub \& Johnson, 2002; D. B. Kandel \& Yamaguchi, 1993; Kennedy et al., 2016; Sartor et al., 2013). Pointed follow-up questions allowed for a more precise determination of the order in the drug-using sequence.

\section{METHODS}

\section{Data and Sample}

Data were from the publicly available 2004-2014 US National Survey on Drug Use and Health (NSDUH), a nationally representative, household-based annual series of crosssectional surveys on drug use and their correlates (United States Department of Health and Human Services, 2016). A multistage area probability sampling design selected designated participants from a target population of civilian, non-institutionalized US residents aged 12 
years and older ( $\mathrm{n}=615,701$ total sampled across survey years). Trained field staff conducted interviews using audio computer-assisted self-interview (ACASI) and computer-assisted personal interview (CAPI) methods to enhance confidentiality and accurate reporting of sensitive behaviors, such as drug use. Participants were compensated $\$ 30$ for completed interviews; the average participation level for 2004-2014 was 65\%. All participants were provided with informed consent and procedures were approved by the appropriate institutional review board for the protection of human subjects. Further details of the NSDUH methodology have been published online (http://www.samhsa.gov/data/populationdata-nsduh/reports?tab=38; last accessed 2702 2018).

The present study focused on a subsample of participants aged 12-21-years-old ( $\mathrm{n}=275,559$; $48 \%$ of the total sampled). Excluded were adults aged 22 or older $(n=318,069)$ due to concerns about accurate age-of-drug onset recall, and participants whose age of first drug used could not be determined due to missing data ( $\mathrm{n}=22,073 ; 7.4 \%$ of $12-21$-year-olds).

\section{Measures}

Initiation of Substance Use-Participants reported age-of-first use for marijuana, cigarettes, other tobacco products (i.e., cigars, snuff, chew, and smokeless tobacco), alcohol, and other drugs (i.e., inhalants, cocaine, heroin, and non-medical prescription drugs) in response to a series of questions that asked: "How old were you when you first used $[d r u g]$ ?". When the age-of-onset for cigarettes, alcohol, and marijuana coincided (i.e., ties), a series of follow-up items were asked. The first item read: "Earlier, the computer recorded that you started using [these substances] when you were [age] years old. Which did you use first?;" the second read: "After first using [first drug], which of these did you use next?". Based on responses to these items, a small value (0.1) was added to the participants' age-ofonset when one drug was reported to occur after another (i.e., making them slightly older). The user-defined rowranks command available in Stata ranked the order of onset for each drug based on the age-of-onset (Cox, 2009; StataCorp, 2013). A variable was constructed to indicate which drug was initiated first (if at all): (1) no drug use, (2) cigarettes, (3) alcohol, (4) marijuana, (5) other tobacco products, (6) other drugs. Seventeen percent of the sample had completed these follow-up items.

Drug-Related Outcomes-Participants were asked about the number of days they had used marijuana in the last 30 days and in the last 12 months. Heavy marijuana use was defined as reporting marijuana use on either $\geq 20$ or more days in the past month, or $\geq 300$ days in the past year. Participants were classified as having a cannabis use disorder (CUD) or alcohol use disorder (AUD) if, within the last 12 months, they had met one or more features of abuse or 3 or more features of dependence based on criteria in the Diagnostic and Statistical Manual of Mental Disorders, $4^{\text {th }}$ Edition (American Psychiatric Association, 1994). Those whose total score on the Nicotine Dependence Syndrome Scale was $\geq 2.75$ were classified as having nicotine dependence (ND) (Shiffman, Waters, \& Hickcox, 2004). Any lifetime use of other drugs was based on responses to items about having ever used inhalants, cocaine, heroin, and non-medical prescription drugs. 
Demographic Factors-We included demographic factors as covariates, including: sex, age at interview, and race/ethnicity. Race/ethnicity categories included White, Black, American Indian or Alaskan Native, Native Hawaiian or Other Pacific Islander, Asian, and Multiracial, all non-Hispanic, and a final category for Hispanic/Latino respondents of any race.

\section{Analyses}

First, we estimated the proportion of youth who initiated substance use with marijuana, cigarettes, alcohol, other tobacco products, and other illicit drugs, and examined variation by demographic characteristics and survey year. Next, we used multinomial logistic regression to estimate the degree to which demographic characteristics and survey year were independently associated with initiating marijuana first, relative to alternative initiation sequences, including: (1) marijuana vs. no drug use, (2) marijuana vs. cigarettes first, and (3) marijuana vs. alcohol first. In these models, the probability or risk of initiating marijuana first compared to one of these alternative sequences (i.e., the reference group) is expressed as a relative risk ratio (RRR), and has a similar interpretation as an odds ratio (Hilbe, 2009). Finally, we explored potential two-way interactions between sex, age, and race/ethnicity.

The second series of analyses examined drug-related outcomes. We used logistic regression to estimate odds ratios (OR) associated with initiating marijuana before other substances for five dichotomous outcomes: (1) heavy cannabis use, (2) CUD, (3) AUD, (4) ND, and (5) lifetime use of other drugs. These models excluded youth who had never used drugs. Adjusted models controlled for sex, age, race/ethnicity, survey year, and the number of drugs used. Age of first marijuana use was adjusted for in models of cannabis-related outcomes, while age of first alcohol, cigarette, and other drug use was similarly adjusted for in models of AUD, ND, and lifetime other drug use, respectively. All analyses accounted for the complex survey design, sampling weights, and were conducted in Stata version 13.0 (StataCorp, 2013).

\section{RESULTS}

For each substance, the mean age of reported first use increased over the study period. The mean age of first marijuana use increased ( +0.5 years) from 14.7 years in 2004 to 15.2 years in 2014; these numbers were comparable to those for age of first use of cigarettes (13.6 vs. $15.0 ;+1.4$ years), alcohol ( 14.4 vs. $15.2 ;+0.8$ years), other tobacco ( 14.8 vs. $15.7 ;+0.9$ years), and other drug use (14.4 vs. $15.0 ;+0.6$ years).

Aggregated across survey years, 5.8\% of respondents reported that they initiated marijuana before other substances, compared to $29.8 \%$ for alcohol, $14.2 \%$ for cigarettes, $3.6 \%$ for other tobacco products, and $5.9 \%$ other drugs (these data are provided in online supplemental Table S1). From 2004 to 2014, the proportion who had initiated marijuana before other substances increased from $4.4 \%$ to $8.0 \%$ (Figure 1), declined for those having initiated cigarettes first (21.4\% to $8.9 \%)$ and increased in youth having abstained from substance use (35.5\% to $46.3 \%)$. Males were more likely than females to have initiated marijuana first (7.1\%) or other tobacco products first $(5.7 \%)$, whereas females were more likely than males to have initiated cigarettes (15.2\%) or alcohol first (32.0\%). Considering age, a small 
proportion of 12-13-year-olds ( $0.6 \%)$ reported initiating marijuana before other substances, but by ages 18-19 and 20-21-years this proportion increased to $9.1 \%$ and $9.4 \%$, respectively. American Indian/Alaskan Native (AI/AN) (11.8\%) and Black youth (9.4\%) had the highest proportion of initiating marijuana first; White (4.6\%) and Asian youth (2.5\% had the lowest).

As shown in Table 1, males were more likely than females to have initiated marijuana first in comparison to those not using drugs ( $a R R R=1.69)$, those initiating cigarettes first $(\mathrm{aRRR}=$ 1.79), or those initiating alcohol first $(\mathrm{aRRR}=1.83)$. Likewise, the likelihood of initiating marijuana first relative to no drug use $(\mathrm{aRRR}=1.69)$ or alcohol first $(\mathrm{aRRR}=1.06)$ increased with age, but not relative to initiating cigarettes first. Compared to Whites, AI/AN youth were 3.7 times more likely to have initiated marijuana first relative to no drug use, and were 5.0 times more likely to have initiated marijuana first relative to alcohol. Notably, Black youth were the most likely to have initiated marijuana first compared to cigarettes (aRRR = 2.74). To a lesser extent, Hispanic, Native Hawaiian/Other Pacific Islander (NHOPI), and multiracial youth also had a higher likelihood of initiating marijuana before other substances compared to Whites. By contrast, Asian youth were less likely to have initiated marijuana first relative to no drug use $(\mathrm{aRRR}=0.30)$ or alcohol first $(\mathrm{aRRR}=$ 0.59). Thus, White and Asian youth were more likely to have initiated cigarettes or alcohol first before other substances compared to other racial/ethnic groups. Even after accounting for these demographic characteristics, the likelihood of initiating marijuana before other substances increased with survey year relative to no drug use (aRRR $=1.01)$ or alcohol first $(\mathrm{aRRR}=1.07)$, but most strongly when compared to cigarettes first $(\mathrm{aRRR}=1.16)$.

In exploratory analyses, we examined subgroup interactions between sex, age, and race/ ethnicity in relation to having initiated marijuana first vs. no drug use (data not in tables). We found no subgroup interactions by sex (i.e., age x sex or race/ethnicity x sex). However, there was less variation by race/ethnicity among older age groups. For example, 20-21-yearold Black youth had a similar likelihood of initiating marijuana first relative to Whites, but 15-16-year-old Black youth had almost twice the likelihood (aRRR $=1.9$ ).

Table 2 shows the degree to which initiating marijuana before other substances is associated with the drug-related outcomes examined, after adjustment for potential confounders. Generally, those who started with a particular substance were the most like to have prevalent problematic use of that substance. For example, those who initiated marijuana before other substances were more likely currently smoke marijuana heavily and have CUD. Those who initiated alcohol before other substances were the most likely to experience prevalent AUD, and those who initiated cigarettes first were the most likely to experience prevalent ND. However, it is worth noting that those who initiated marijuana first were no less likely, statistically, to have prevalent ND as compared to those who initiated cigarettes first. Finally, youth who initiated cigarettes or other tobacco products before other substances were less likely than those starting with alcohol or marijuana to have used other drugs, such as cocaine, heroin, inhalants, and non-medical prescription drugs. 


\section{DISCUSSION}

We found that, in 2014, $8 \%$ of US youths aged 12-21-years reported that marijuana was the first drug they used; this percentage has almost doubled since 2004 . This increase could be due to a concurrent decline in those starting with cigarettes first, which dropped from about $21 \%$ to $9 \%$ over the same period. The proportion of youth initiating other tobacco products or other drugs first also declined, but to a limited extent, and there has been little change in the proportion of youth who start with alcohol first, which remained the substance youth most commonly initiate first. We also observed a significant increase in youth abstaining from substance use altogether, which rose from $36 \%$ to $46 \%$, and therefore, it is unclear the degree to which increases in those initiating marijuana first could be due to youth abstaining or delaying cigarette smoking (Johnson et al., 2018). Higher levels of perceived risk for cigarettes compared to marijuana could be a contributing factor (Berg et al., 2015; Pacek, Mauro, \& Martins, 2015). Our estimate is slightly lower than a previous estimate produced a decade ago (Gfroerer, Wu, \& Penne, 2002); however, this prior study looked only at those who started smoking marijuana within the last 12 months, which might overestimate the number who used marijuana before cigarettes or alcohol.

We found that males and older youth were more likely to start with marijuana as their first drug. Males report more opportunities to try marijuana and are less likely to perceive it as harmful than females, and therefore, lead to an increased likelihood of starting with marijuana before other substances (Pacek et al., 2015; Van Etten \& Anthony, 2001). We also found that as youth aged, they were more likely to start with marijuana as their first drug compared to no drug use or using alcohol first. This could be explained by a number of agerelated factors, such as greater perceived availability of marijuana and lower perceived harm relative to cigarettes and alcohol at older ages (Johnston et al., 2017). There are also important differences in the legal age of being able to purchase cigarettes (18 years) and alcohol (21 years) which may help explain why age was not significantly related to starting with marijuana first compared to cigarettes.

With the exception of Asian youth, racial/ethnic minority youth were generally more likely than White youth to start with marijuana. American Indian or Alaskan Native (AI/AN) youth were the most likely to use marijuana first relative to no drug use or using alcohol first, but Black youth were more likely to use marijuana first compared to cigarettes first. Using data on $8^{\text {th }}, 10^{\text {th }}$, and $12^{\text {th }}$ graders in Washington state covering roughly the same time period (2004-2016), Johnson and colleges (2018) in the present issue corroborate higher rates of past 30-day marijuana among AI/AN and Black youth. American Indian youth perceive less disapproval from using marijuana by their classmates and adults compared to White youth, which might help explain our findings, is consistent with studies showing high rates of marijuana use in this group, and a greater likelihood of AI youth using marijuana before alcohol (Johnson et al., 2015; Novins, Beals, \& Mitchell, 2001; Stanley, Harness, Swaim, \& Beauvais, 2014; Swaim, Stanley, \& Beauvais, 2013).

Black youth also had a greater chance of starting with marijuana than Whites, especially compared to using cigarettes or alcohol first, which is consistent with other literature on who uses marijuana before tobacco (Golub \& Johnson, 2002; Kennedy et al., 2016; Vaughn et al., 
2008; White, Jarrett, Valencia, Loeber, \& Wei, 2007). White youth are more likely to drink, smoke cigarettes, and start using both substances at younger ages than Blacks (Dawson, 1998; Landrine, Richardson, Klonoff, \& Flay, 1994; Roberts, Colby, Lu, \& Ferketich, 2016). Tolerance of situational norms and attitudes towards drinking and drunkenness are also greater among White compared to Black youth, and White peers may exert a larger influence on tobacco and alcohol behaviors compared to Black peers (Caetano \& Clark, 1999;

Gibbons et al., 2010). Black parents are more likely than those of other races to abstain from alcohol use, and are also less likely to involve their children in family alcohol use (Peterson, Hawkins, Abbott, \& Catalano, 1994). Marijuana may be more available in Black neighborhoods and be perceived as less stigmatizing and harmful than tobacco or alcohol, which might make it a more socially acceptable alternative to tobacco and alcohol as a coping mechanism for greater victimization, discrimination, and social stress in their environment (Boardman \& Alexander, 2011; Furr-Holden et al., 2011; Green et al., 2016; Peterson et al., 1994; Reboussin et al., 2015; Sinclair, Foushee, Scarinci, \& Carroll, 2013; Stock, Gibbons, Walsh, \& Gerrard, 2011; Storr, Chen, \& Anthony, 2004). However, exploratory findings reveal that these race/ethnic differences may be more pronounced among younger adolescents (e.g., 15-16-year-olds).

Starting with marijuana first may increase the likelihood of heavy and problematic use. Even after accounting for demographics, age of marijuana onset, and the number of drug used, our results showed those who initiated marijuana first before other substances were more likely to smoke marijuana daily or near daily and currently experience CUD. In explaining these findings, it is possible that the substance youth try first might positively influence their preference and attitudes about that drug relative to others and lead them to become persistent and dependent users of that drug sooner than for substances that are tried later.

Unfortunately, because our data were cross-sectional, we could not fill in the gap about youths' substance use between their first use and current experience. Nonetheless, this idea is consistent with our other findings showing that those who start with alcohol first or cigarettes first tend to be the most likely to have prevalent AUD and ND, respectively. It is also consistent with the finding by Sartor and colleagues (2013) that women who started with marijuana before alcohol progressed more rapidly to onset of marijuana problems than those exhibiting the reverse sequence.

However, our findings suggest that in terms of ND, there may be little difference between those who start with marijuana and later smoke cigarettes, and vice versa. Our results showed that that those who started with marijuana first were statistically no less likely than those who started with cigarettes first to be nicotine dependent. High levels of co-use could be one explanation with $90 \%$ of lifetime marijuana users reporting cigarette smoking sometime in their life (Agrawal, Budney, \& Lynskey, 2012). Youth who start with marijuana may also have an easier and quicker time transitioning to smoking tobacco compared to other substances. Both drugs share a similar, and thus familiar, route of administration and the two drugs can be easily mixed together within a single preparation (e.g., blunts, spliffs) (Agrawal \& Lynskey, 2009). As shown in the paper by Nguyen and other in the present issue, adolescent marijuana use increases the risk of daily cigarette smoking in women. Once regular cigarette smoking starts, the onset of ND symptoms can occur relatively 
quickly - within four weeks according to one study (DiFranza, 2000) - unlike for CUD and AUD, which may take several years to develop (Wagner \& Anthony, 2002a).

We also find that those who start with marijuana or with alcohol are equally more likely to subsequently use other drugs, such as cocaine, heroin, inhalants, or non-medical prescription drugs, compared to a lower likelihood for those who start with cigarettes or other tobacco products. Alcohol, like marijuana, has been implicated as a "gateway" drug for illegal drug use (D. B. Kandel \& Kandel, 2015; Kirby \& Barry, 2012), although critics point to alternative explanations for this relationship including the order in which youth have the opportunity to use different drugs and the role of common liability phenotypes (Morral, McCaffrey, \& Paddock, 2002; Vanyukov \& Ridenour, 2012). For example, youth who start with marijuana or alcohol may have more opportunities to try other illegal drugs via increased exposure to illegal markets or drug-using peers (Caulkins \& Pacula, 2006; Wagner $\&$ Anthony, 2002b). Alcohol and marijuana may also have neurocognitive effects on adolescent brain development that impair behavioral control and lead to riskier decisionmaking, such as engaging in more serious drug use (Bava \& Tapert, 2010).

Before further discussion of this study's implications, these findings should be viewed within the context of the following limitations. First, these data are based on retrospective self-report, and accuracy of recall for the age of substance onset could be subject to forward telescoping bias (i.e., reporting events as being closer in time than what is true) although it is unclear if this bias differs by the drug, their sequence, or the number of drugs used (Shillington, Woodruff, Clapp, Reed, \& Lemus, 2012). By restricting the sample to 12-21year-olds, we sought to limit issues with recall, so as most youth would have initiated their first drug use within the last few years. Second, we were only able to explore prevalent outcomes associated with using marijuana first, rather than the first onset of symptoms or disordered use, which may conflate effects on incidence versus duration. That is, we cannot account for the possibility that some who start with marijuana first may rapidly progress to heavy use, CUD, or other outcomes, but then be in remission within the year prior to interview when these outcomes were assessed. Third, analyses of potential confounders were limited to a few time-invariant demographic characteristics, since the NSDUH was not designed to assess other time-invariant or time-varying factors (e.g., parental, peer, mental health, or socioeconomic factors) present before the first drug onset, and which might help explain both using marijuana first and related outcomes.

We conclude by mentioning notable study strengths and raise future implications for research, prevention, and treatment. Strengths include the use of large, representative samples and consistent methods across surveys that aided in promoting valid, precise, and generalizable estimates of sensitive behaviors, such as drug use. This paper demonstrates the advantage of focused follow-up questions to refine the drug onset sequence when the age of first use responses overlap. Our findings suggest important targets for public health intervention and prevention of marijuana use, especially among American Indian/Alaska Native and Black youth, who are less likely to have access to treatment or successful treatment outcomes (Peters, Hendricks, Clark, Vocci, \& Cropsey, 2014; Priester et al., 2016; Vendetti, McRee, Miller, Christiansen, \& Herrell, 2002). Specifically, drug prevention strategies may need to be better targeted to groups differently based on their risk of initiating 
tobacco, alcohol, or marijuana first. To the degree these trends continue and greater numbers of youth start with marijuana as their first drug, there may be an increasing need for public interventions and treatment services for marijuana-related problems.

\section{Supplementary Material}

Refer to Web version on PubMed Central for supplementary material.

\section{Acknowledgments}

Funding

Dr. Fairman's contribution to this work was supported by a grant from the National Institute on Drug Abuse (T32DA007292) and the Intramural Research Program of the Eunice Kennedy Shriver National Institute for Child Health and Human Development. Dr. Johnson is supported by a K01DA031738 NIDA grant, and Dr. Furr-Holden is supported by a R01CE002682 grant from the CDC National Center for Injury Prevention and Control.

\section{References}

Agrawal A, Budney AJ, Lynskey MT. 2012; The co-occurring use and misuse of cannabis and tobacco: a review. Addiction. 107(7):1221-1233. DOI: 10.1111/j.1360-0443.2012.03837.x [PubMed: 22300456]

Agrawal A, Lynskey MT. 2009; Tobacco and cannabis co-occurrence: Does route of administration matter? Drug and Alcohol Dependence. 99(1-3):240-247. DOI: 10.1016/j.drugalcdep.2008.08.007 [PubMed: 18926646]

American Psychiatric Association. Diagnostic and Statistical Manual of Mental Disorders. 4. Washington, DC: 1994.

Bava S, Tapert SF. 2010; Adolescent brain development and the risk for alcohol and other drug problems. Neuropsychology Review. 20(4):398-413. DOI: 10.1007/s11065-010-9146-6 [PubMed: 20953990]

Berg CJ, Stratton E, Schauer GL, Lewis M, Wang Y, Windle M, Kegler M. 2015; Perceived Harm, Addictiveness, and Social Acceptability of Tobacco Products and Marijuana Among Young Adults: Marijuana, Hookah, and Electronic Cigarettes Win. Substance Use \& Misuse. 50(1):79-89. DOI: 10.3109/10826084.2014.958857 [PubMed: 25268294]

Boardman JD, Alexander KB. 2011; Stress trajectories, health behaviors, and the mental health of black and white young adults. Social Science \& Medicine. 72(10):1659-1666. DOI: 10.1016/ j.socscimed.2011.03.024 [PubMed: 21514025]

Caetano R, Clark CL. 1999; Trends in situational norms and attitudes toward drinking among Whites, Blacks, and Hispanics: 1984-1995. Drug and Alcohol Dependence. 54(1):45-56. [PubMed: 10101616]

Caulkins JP, Pacula RL. 2006; Marijuana markets: Inferences from reports by the household population. Journal of Drug Issues. 36(1):173-200.

Cox NJ. 2009; Speaking Stata: Rowwise. Stata Journal. 9(1):137.

Dawson DA. 1998; Beyond Black, White and Hispanic: Race, ethnic origin and drinking patterns in the United States. Journal of Substance Abuse. 10(4):321-339. [PubMed: 10897287]

Degenhardt L, Chiu WT, Conway K, Dierker L, Glantz M, Kalaydjian A, ... Kessler RC. 2009; Does the 'gateway' matter? Associations between the order of drug use initiation and the development of drug dependence in the National Comorbidity Study Replication. Psychological Medicine. 39(01):157-167. [PubMed: 18466664]

Degenhardt L, Dierker L, Chiu WT, Medina-Mora ME, Neumark Y, Sampson N, ... Kessler RC. 2010; Evaluating the drug use "gateway" theory using cross-national data: Consistency and associations of the order of initiation of drug use among participants in the WHO World Mental Health Surveys. Drug and Alcohol Dependence. 108(1-2):84-97. DOI: 10.1016/j.drugalcdep.2009.12.001 [PubMed: 20060657] 
Ellgren M, Spano SM, Hurd YL. 2007; Adolescent cannabis exposure alters opiate intake and opioid limbic neuronal populations in adult rats. Neuropsychopharmacology. 32(3):607-615. [PubMed: 16823391]

Friend KB, Lipperman-Kreda S, Grube JW. 2011; The Impact of Local US Tobacco Policies on Youth Tobacco Use: A Critical Review. Open J Prev Med. 1(2):34-43. DOI: 10.4236/ojpm.2011.12006 [PubMed: 22200035]

Furr-Holden CDM, Lee MH, Milam AJ, Johnson RM, Lee KS, Ialongo NS. 2011; The Growth of Neighborhood Disorder and Marijuana Use Among Urban Adolescents: A Case for Policy and Environmental Interventions. Journal of Studies on Alcohol and Drugs. 72(3):371-379. [PubMed: 21513673]

Gfroerer, JC, Wu, L-T, Penne, MA. Initiation of Marijuana Use: Trends, Patterns, and Implications. Rockville, MD: Substance Abuse and Mental Health Services Administration, Office of Applied Studies; 2002.

Gibbons FX, Pomery EA, Gerrard M, Sargent JD, Weng CY, Wills TA, ... Yeh H-C. 2010; Media as social influence: racial differences in the effects of peers and media on adolescent alcohol cognitions and consumption. Psychology of Addictive Behaviors. 24(4):649. [PubMed: 21198226]

Golub A, Johnson BD. 2002; The misuse of the 'gateway theory' in US policy on drug abuse control: a secondary analysis of the muddled deduction. International Journal of Drug Policy. 13(1):5-19.

Green KM, Johnson RM, Milam AJ, Furr-Holden D, Ialongo NS, Reboussin BA. 2016; Racial Differences and the Role of Neighborhood in the Sequencing of Marijuana and Tobacco Initiation Among Urban Youth. Substance Abuse. 37(4):507-510. DOI: 10.1080/08897077.2016.1178680 [PubMed: 27092865]

Hilbe, JM. Logistic Regression Models. CRC Press; 2009.

Hingson R, White A. 2014; New Research Findings Since the 2007 Surgeon General's Call to Action to Prevent and Reduce Underage Drinking: A Review. Journal of Studies on Alcohol and Drugs. 75(1):158-169. DOI: 10.15288/jsad.2014.75.158 [PubMed: 24411808]

Johnson RM, Fairman B, Gilreath T, Xuan Z, Rothman EF, Parnham T, Furr-Holden CDM. 2015; Past 15 -year trends in adolescent marijuana use: Differences by race/ethnicity and sex. Drug and Alcohol Dependence. 155:8-15. DOI: 10.1016/j.drugalcdep.2015.08.025 [PubMed: 26361714]

Johnson, RM; Fleming, CB; Cambron, C; Brighthaupt, S-C; Dean, LT; Guttmannova, K. Race/ ethnicity differences in trends of alcohol, cigarette, and marijuana use among adolescents in Washington state, 2004-2014. Prevention Science. 2018. (Accepted for Publication). https:// doi.org/doi not yet assigned

Johnston, LD, O’Malley, PM, Miech, RA, Bachman, JG, Schulenberg, JE. Monitoring the Future national survey results on drug use, 1975-2016: Overview, key findings on adolescent drug use. Ann Arbor, MI: Institute for Social Research, The University of Michigan; 2017.

Kandel DB, Kandel ER. 2015; The Gateway Hypothesis of substance abuse: developmental, biological and societal perspectives. Acta Paediatrica. 104(2):130-137. [PubMed: 25377988]

Kandel DB, Yamaguchi K. 1993; From beer to crack: developmental patterns of drug involvement. American Journal of Public Health. 83(6):851-855. [PubMed: 8498623]

Kandel ER, Kandel DB. 2014; A molecular basis for nicotine as a gateway drug. New England Journal of Medicine. 371(10):932-943. [PubMed: 25184865]

Kennedy SM, Patel RP, Cheh P, Hsia J, Rolle IV. 2016; Tobacco and marijuana initiation among African American and white young adults. Nicotine \& Tobacco Research. 18(suppl 1):S57-S64. [PubMed: 26391577]

Kirby T, Barry AE. 2012; Alcohol as a Gateway Drug: A Study of US 12th Graders. Journal of School Health. 82(8):371-379. DOI: 10.1111/j.1746-1561.2012.00712.x [PubMed: 22712674]

Landrine H, Richardson JL, Klonoff EA, Flay B. 1994; Cultural diversity in the predictors of adolescent cigarette smoking: the relative influence of peers. Journal of Behavioral Medicine. 17(3):331-346. [PubMed: 7932684]

Morral A, McCaffrey D, Paddock S. 2002; Reassessing the marijuana gateway effect. Addiction. 97(12):1493-1504. [PubMed: 12472629] 
Nguyen, TQ; Ebnesajjad, C; Stuart, EA; Kennedy, RD; Johnson, RM. Does Marijuana Use at Ages 16-18 Predict Initiation of Daily Cigarette Smoking in Late Adolescence and Early Adulthood? A Propensity Score Analysis of Add Health Data. Prevention Science. 2018.

Novins DK, Beals J, Mitchell CM. 2001; Sequences of Substance Use Among American Indian Adolescents. Journal of the American Academy of Child \& Adolescent Psychiatry. 40(10):11681174. DOI: 10.1097/00004583-200110000-00010 [PubMed: 11589529]

Pacek LR, Mauro PM, Martins SS. 2015; Perceived risk of regular cannabis use in the United States from 2002 to 2012: differences by sex, age, and race/ethnicity. Drug and Alcohol Dependence. 149:232-244. DOI: 10.1016/j.drugalcdep.2015.02.009 [PubMed: 25735467]

Panlilio LV, Zanettini C, Barnes C, Solinas M, Goldberg SR. 2013; Prior Exposure to THC Increases the Addictive Effects of Nicotine in Rats. Neuropsychopharmacology. 38(7):1198-1208. DOI: 10.1038/npp.2013.16 [PubMed: 23314220]

Patton GC, Coffey C, Carlin JB, Sawyer SM, Lynskey M. 2005; Reverse gateways? Frequent cannabis use as a predictor of tobacco initiation and nicotine dependence. Addiction. 100(10):1518-1525. [PubMed: 16185213]

Peters EN, Hendricks PS, Clark CB, Vocci FJ, Cropsey KL. 2014; Association of Race and Age With Treatment Attendance and Completion Among Adult Marijuana Users in Community-Based Substance Abuse Treatment. Journal of Addiction Medicine. 8(2):143-149. [PubMed: 24603621]

Peterson PL, Hawkins JD, Abbott RD, Catalano RF. 1994; Disentangling the Effects of Parental Drinking, Family Management, and Parental Alcohol Norms on Current Drinking by Black and White Adolescents. Journal of Research on Adolescence. 4(2):203-227. DOI: 10.1207/ s15327795jra0402_3

Priester MA, Browne T, Iachini A, Clone S, DeHart D, Seay KD. 2016; Treatment Access Barriers and Disparities Among Individuals with Co-occurring Mental Health and Substance Use Disorders: An Integrative Literature Review. Journal of Substance Abuse Treatment. 61:47.doi: 10.1016/j.jsat. 2015.09.006 [PubMed: 26531892]

Ramo DE, Liu H, Prochaska JJ. 2012; Tobacco and marijuana use among adolescents and young adults: A systematic review of their co-use. Clinical Psychology Review. 32(2):105-121. DOI: 10.1016/j.cpr.2011.12.002 [PubMed: 22245559]

Reboussin BA, Green KM, Milam AJ, Furr-Holden DM, Johnson RM, Ialongo NS. 2015; The role of neighborhood in urban black adolescent marijuana use. Drug and Alcohol Dependence. 154:6975. DOI: 10.1016/j.drugalcdep.2015.06.029 [PubMed: 26162651]

Roberts ME, Colby SM, Lu B, Ferketich AK. 2016; Understanding tobacco use onset among African Americans. Nicotine \& Tobacco Research. 18(suppl 1):S49-S56. [PubMed: 26980864]

Sartor CE, Agrawal A, Lynskey MT, Duncan AE, Grant JD, Nelson EC, ... Bucholz KK. 2013; Cannabis or alcohol first? Differences by ethnicity and in risk for rapid progression to cannabisrelated problems in women. Psychological Medicine. 43(4):813-823. DOI: 10.1017/ S0033291712001493 [PubMed: 22804877]

Shiffman S, Waters AJ, Hickcox M. 2004; The Nicotine Dependence Syndrome Scale: A multidimensional measure of nicotine dependence. Nicotine \& Tobacco Research. 6(2):327-348. DOI: 10.1080/1462220042000202481 [PubMed: 15203807]

Shillington AM, Woodruff SI, Clapp JD, Reed MB, Lemus H. 2012; Self-reported age of onset and telescoping for cigarettes, alcohol, and marijuana: across eight years of the national longitudinal survey of youth. Journal of Child \& Adolescent Substance Abuse. 21(4):333-348. [PubMed: 23284228]

Sinclair CF, Foushee HR, Scarinci I, Carroll WR. 2013; Perceptions of harm to health from cigarettes, blunts, and marijuana among young adult African American men. Journal of Health Care for the Poor and Underserved. 24(3):1266-1275. DOI: 10.1353/hpu.2013.0126 [PubMed: 23974397]

Stanley LR, Harness SD, Swaim RC, Beauvais F. 2014; Rates of substance use of American Indian students in 8th, 10th, and 12th grades living on or near reservations: update, 2009-2012. Public Health Reports (Washington, DC: 1974). 129(2):156-163. DOI: 10.1177/003335491412900209

StataCorp. Stata Statistical Software: Release 13. College Station, TX: StataCorp, LP; 2013. 
Stock ML, Gibbons FX, Walsh LA, Gerrard M. 2011; Racial identification, racial discrimination, and substance use vulnerability among African American young adults. Personality and Social Psychology Bulletin. 37(10):1349-1361. [PubMed: 21628598]

Storr CL, Chen CY, Anthony JC. 2004; "Unequal opportunity": Neighbourhood disadvantage and the chance to buy illegal drugs. Journal of Epidemiology and Community Health. 58(3):231-237. [PubMed: 14966238]

Substance Abuse and Mental Health Services Administration. Key substance use and mental health indicators in the United States: Results from the 2016 National Survey on Drug Use and Health. Rockville, MD: Center for Behavioral Health Statistics and Quality, Substance Abuse and Mental Health Services Administration; 2017. No. HSS Publication No. SMA 17-5044, NSDUH Series H-52Retrieved from http://www.samhsa.gov/data

Swaim RC, Stanley LR, Beauvais F. 2013; The normative environment for substance use among American Indian students and white students attending schools on or near reservations. The American Journal of Orthopsychiatry. 83(2 Pt 3):422-429. DOI: 10.1111/ajop.12022 [PubMed: 23889032]

Timberlake DS, Haberstick BC, Hopfer CJ, Bricker J, Sakai JT, Lessem JM, Hewitt JK. 2007; Progression from marijuana use to daily smoking and nicotine dependence in a national sample of US adolescents. Drug and Alcohol Dependence. 88(2-3):272-281. DOI: 10.1016/j.drugalcdep. 2006.11.005 [PubMed: 17174040]

United States Department of Health and Human Services. National Survey on Drug Use and Health, 2010-2014. Ann Arbor, MI: Inter-university Consortium for Political and Social Research [distributor]; 2016. Retrieved from https://www.icpsr.umich.edu/icpsrweb/ICPSR/series/64

Van Etten ML, Anthony JC. 2001; Male-female differences in transitions from first drug opportunity to first use: searching for subgroup variation by age, race, region, and urban status. Journal of Women's Health \& Gender-Based Medicine. 10(8):797-804.

Vanyukov MM, Ridenour TA. 2012; Common liability to drug addictions: Theory, research, practice. Drug and Alcohol Dependence. 123(Supplement 1):S1-S2. DOI: 10.1016/j.drugalcdep. 2012.01.005 [PubMed: 22310010]

Vaughn M, Wallace J, Perron B, Copeland V, Howard M. 2008; Does marijuana use serve as a gateway to cigarette use for high-risk African-American youth? The American Journal of Drug and Alcohol Abuse. 34(6):782-791. DOI: 10.1080/00952990802455477 [PubMed: 19016184]

Vendetti J, McRee B, Miller M, Christiansen K, Herrell J. 2002; Correlates of pre-treatment drop-out among persons with marijuana dependence. Addiction. 97(s1):125-134. [PubMed: 12460134]

Wagner FA, Anthony JC. 2002a; From first drug use to drug dependence: Developmental periods of risk for dependence upon marijuana, cocaine, and alcohol. Neuropsychopharmacology. 26(4):479488. [PubMed: 11927172]

Wagner FA, Anthony JC. 2002b; Into the world of illegal drug use: exposure opportunity and other mechanisms linking the use of alcohol, tobacco, marijuana, and cocaine. American Journal of Epidemiology. 155(10):918. [PubMed: 11994231]

Wells JE, McGee MA. 2008; Violations of the usual sequence of drug initiation: prevalence and associations with the development of dependence in the New Zealand Mental Health Survey. Journal of Studies on Alcohol and Drugs. 69(6):789. [PubMed: 18925336]

White HR, Jarrett N, Valencia EY, Loeber R, Wei E. 2007; Stages and sequences of initiation and regular substance use in a longitudinal cohort of black and white male adolescents. Journal of Studies on Alcohol and Drugs. 68(2):173-181. [PubMed: 17286335] 


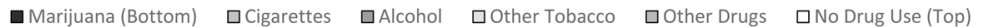

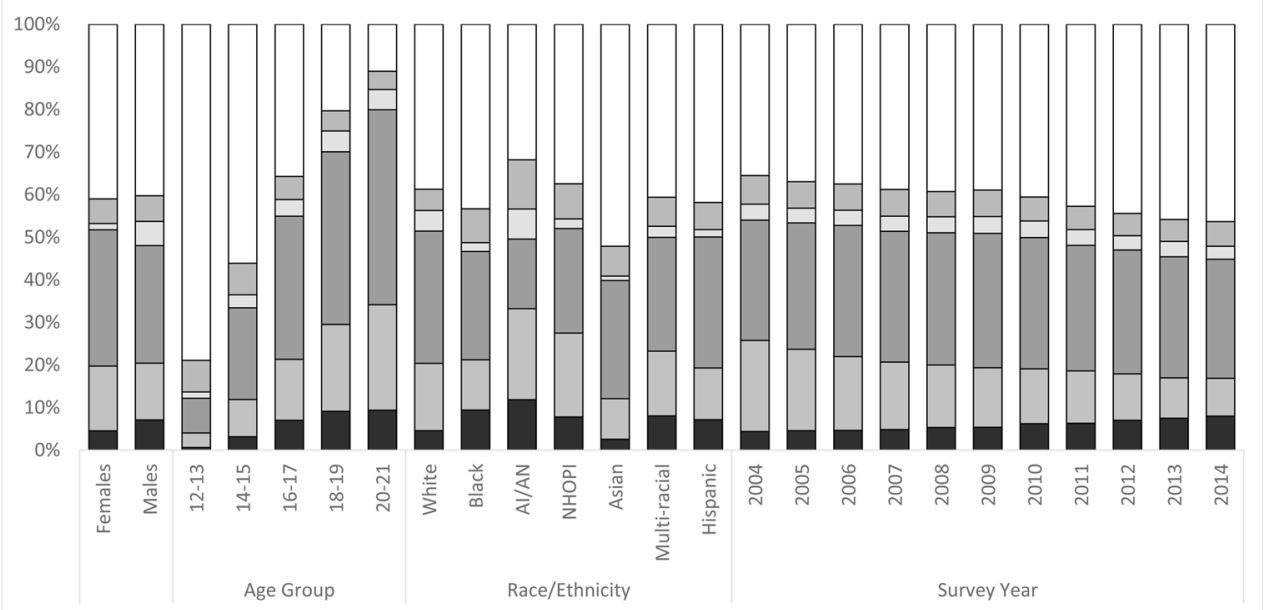

Figure 1.

Percent of youth aged 12-21-years whose first drug use was marijuana, cigarettes, alcohol, other tobacco, other drugs, or no drug use by demographic characteristics and survey year. Abbreviations: American Indian/Alaska Native (AI/AN); Native Hawaiian and other Pacific Islander (NHOPI). 


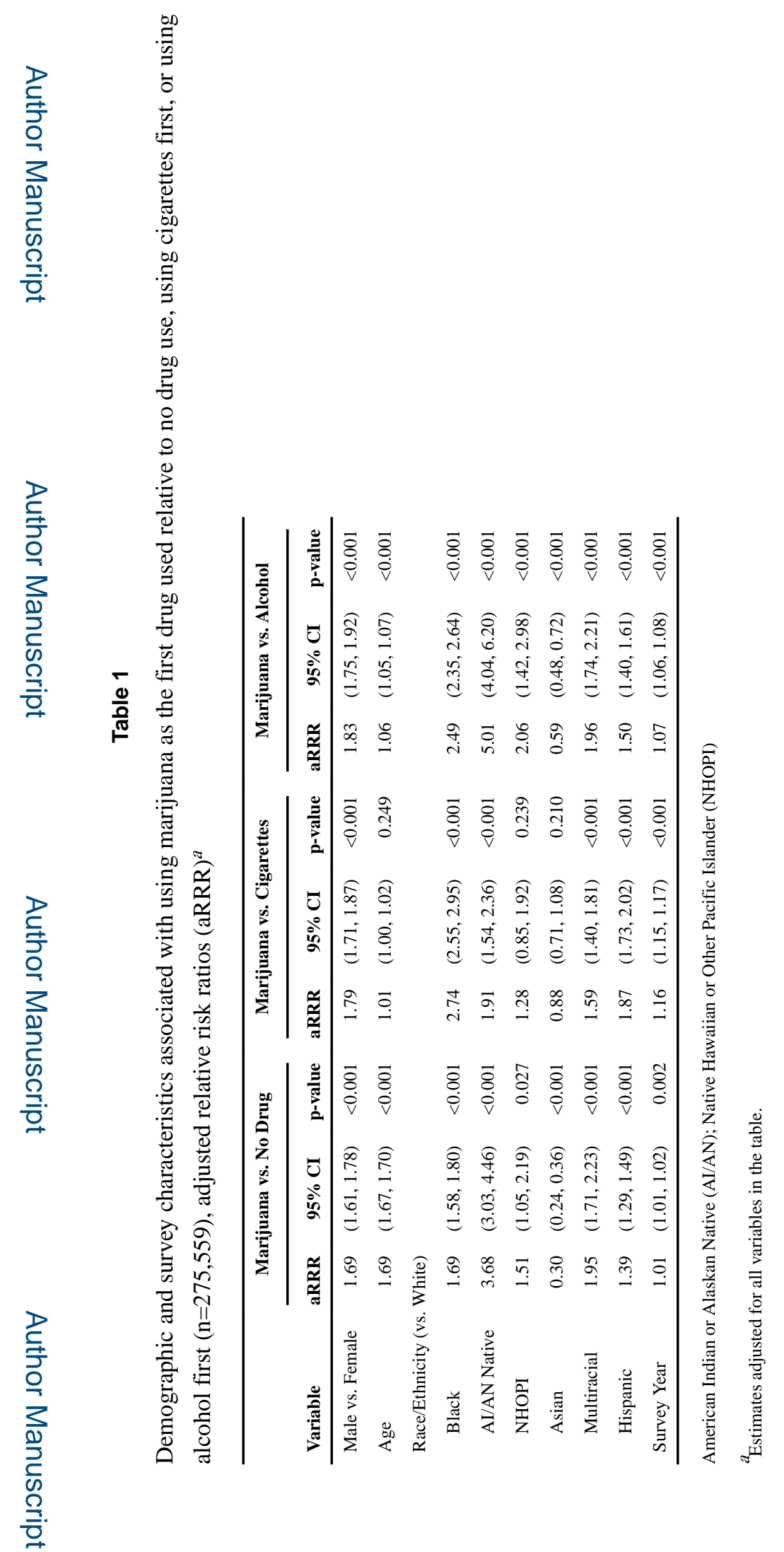

Prev Sci. Author manuscript; available in PMC 2020 February 01. 
Fairman et al.

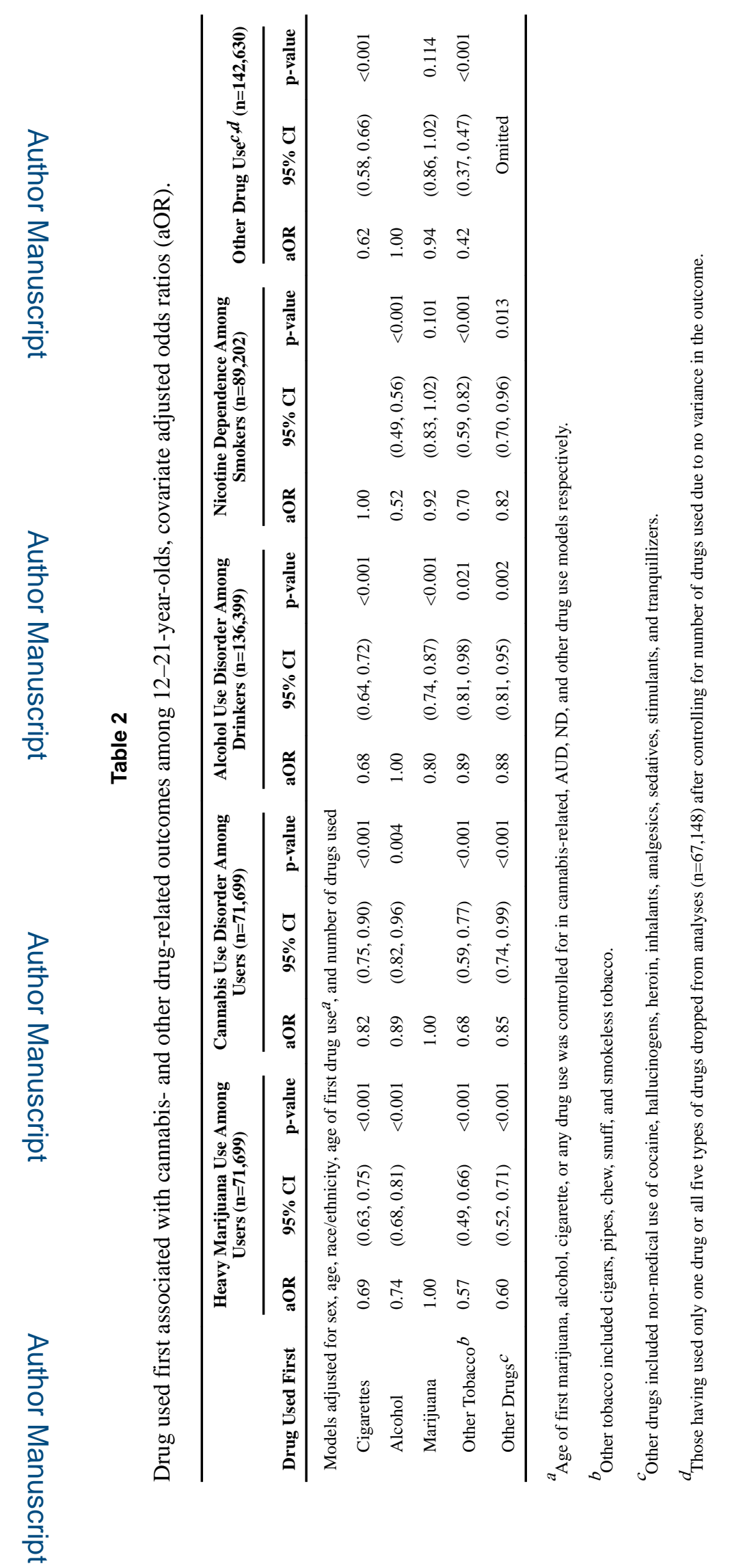

Prev Sci. Author manuscript; available in PMC 2020 February 01. 